\title{
Updates on chronic non-cancer pain management in face of the opioid crisis
}

\author{
Gayathri Sivakumar, Alexandra Budure, Elise Quint
}

\begin{abstract}
Chronic pain not associated with malignancy is experienced by a significant proportion of the Canadian population. As the quality of life and physical functioning are markedly impaired in patients with chronic non-cancer pain, clinicians have commonly turned to opioid therapy for pain management. Since the 1990s, the steady increase in dispensing of prescription opioids has paralleled trends in opioid-related hospitalizations, overdoses, and fatalities. In fact, over-prescription and longterm opioid therapy are among the many root causes fueling Canada's rise in opioid addiction and opioid-related deaths. Physicians and medical regulators have responded to this public health crisis by developing the 2017 Canadian Guideline for Opioids for Chronic Non-Cancer Pain. The new evidencebased guideline aims to encourage safe prescribing practices, reduce and eliminate the use of opioid analgesics and promote non-opioid pharmacotherapy. While clear clinical guidelines will optimize physician prescribing patterns, it is imperative to recognize the need for non-pharmacological modalities for pain management, treatment, and care to holistically address the complex roots of opioid abuse.
\end{abstract}

\section{INTRODUCTION}

Chronic non-cancer pain (CNCP) is defined as any painful condition that persists for a minimum of three months and is not associated with malignancy. ${ }^{1}$ A Canadian population-based study using data gathered between 1994 and 2008 reported that $15-19 \%$ of adults experienced chronic non-cancer pain at any given time. ${ }^{2}$ CNCP has bearings on health and financial costs at an individual and population level. Suffering from chronic pain impedes activities of daily living, diminishes physical capacity and quality of life, and enhances disease burden. ${ }^{3}$ From an economy standpoint, CNCP is one of the foremost causes of healthcare resource consumption and disability among adults in the working-age group. ${ }^{4,5}$

\section{OPIOID THERAPY IN NON-MALIGNANT CHRONIC PAIN}

In North America, physicians have commonly depended on opioids for acute, palliative and chronic pain management. ${ }^{1}$ When all indications for opioid therapy are included, Canada is the second-highest per capita consumer of opiate analgesics in the world, trailing behind the United States. ${ }^{6}$ High-dose dispensing of morphine, hydromorphone, oxycodone, and fentanyl have increased by $23 \%$ between 2006 and 2011 across Canada. ${ }^{7}$ Albeit there is evidence for the efficacy of opioids in treatment of severe, post-surgical or traumatic acute pain, little evidence supports long- term opioid therapy in the context of CNCP management. ${ }^{8-9}$ The sharp increase in prescription opioid analgesic use since the 1990s can be partly explained by aggressive pharmaceutical marketing strategies that encouraged primary care physicians to identify and treat chronic pain with opioids, despite a lack of evidence for using opioids for this indication. ${ }^{10}$

In 2015, Canadian physicians prescribed opioids 53 times for every 100 people in Canada. ${ }^{11}$ In Vancouver, BC, a growing trend in the availability of prescription opioids in people who inject drugs is evident between 2010 and 2014. ${ }^{12}$ Nonmedical prescription opioid use (NMPOU) was significant among street youth and adults, and more than one-third of these individuals engaging in NMPOU had initiated the use of prescription opioids prior to illegal drug use. ${ }^{13}$ Use of opioid analgesics for CNCP may foster drug tolerance and lead to the prescription of higher-than-recommended doses, increased use of illicit opioids, iatrogenic addiction, accidental poisonings, and fatal overdoses. ${ }^{14}$ Hospital visits and treatment admission rates for opioid poisoning has increased by over $30 \%$ in the period between 2007 and $2015 .^{15}$ In Ontario, the number of opioid-related deaths per year (excluding heroin-related fatality) has increased from 127 in 1991 to 540 in 2010, and this number continues to rise. ${ }^{716}$ Of the Ontarian patients under social assistance, 1 in 550 patients initiated on long-term opioid therapy faced opioid-related mortality at a median of 2.6 years from the first opioid prescription. ${ }^{17}$ Nationally, the Public Health Agency of Canada reported 2,458 opioid-related fatalities in $2016 .^{18,19}$

\section{CLINICAL GUIDELINES FOR CHRONIC NON-CANCER PAIN MANAGEMENT}

The emergence of the opioid epidemic created a strong sense of urgency among clinicians and medical regulators to establish prescribing guidelines for CNCP. In 2010, recommendations proposed by the National Opioid Use Guideline Group for safe and effective opioid utilization was adopted. ${ }^{1}$ As the opioid crisis became more pronounced, critics argued that many of the prescribing recommendations from the 2010 Canadian Guideline were ambiguous, liberal with opioid use, and most importantly, eminence-based rather than evidence-based. ${ }^{1}$ Researchers from the McMaster G. DeGroote National Pain Centre have revised the 2010 Canadian Guideline and incorporated evidence-based findings to provide a focused framework for safe opioid prescribing practices for CNCP management. ${ }^{1}$

The 2017 Canadian Guideline for Opioids for Chronic NonCancer Pain follows standards for trustworthy guidelines and is comprised of three categories of guidance: recommendations, good practice statements, and expert guidance. ${ }^{1}$ This guideline provides 
clinicians with ten recommendations which are supported by evidence from randomized controlled trials or observational studies. Additionally, these recommendations are categorized according to the Grading of Recommendations Assessment, Development and Evaluation (GRADE) system as strong or weak recommendations. Seven of the ten recommendations target harm reduction measures. As well, only four of the ten are strong recommendations. Several suggestions focus on maximizing non-opioid therapy for analgesia and on adding a trial of opioid therapy in patients without substance use and psychiatric disorders who have persistent pain despite optimized non-opioid pharmacotherapy. ${ }^{1}$

Table 1. Summary of Canadian Guideline for Opioids for Chronic Non-Cancer Pain

\begin{tabular}{|c|c|}
\hline Recommendation & $\begin{array}{c}\text { Strength of } \\
\text { Recommendation }\end{array}$ \\
\hline $\begin{array}{l}\text { 1. Strong evidence exists to support } \\
\text { maximization of non-opioid } \\
\text { pharmacotherapy and nonpharmacologic } \\
\text { therapy, rather than a trial of opioid } \\
\text { therapy. }\end{array}$ & Strong \\
\hline $\begin{array}{l}\text { 2. For patients who have continual pain, } \\
\text { despite optimization of non-opioid } \\
\text { treatment, there is evidence to propose a } \\
\text { trial of opioids and monitor for response. } \\
\text { Opioid therapy should be terminated if } \\
\text { there is no improvement in pain or } \\
\text { function. }\end{array}$ & Weak \\
\hline $\begin{array}{l}\text { 3. There is strong evidence against the } \\
\text { prescription of opioids for patients with an } \\
\text { active substance abuse disorder. }\end{array}$ & Strong \\
\hline $\begin{array}{l}\text { 4. For patients with an active substance } \\
\text { abuse disorder who experience pain even } \\
\text { with optimized non-opioid therapy, the } \\
\text { psychiatric disorder should be addressed } \\
\text { before considering a trial of opioids. }\end{array}$ & Weak \\
\hline $\begin{array}{l}\text { 5. For patients with a history of substance } \\
\text { abuse disorder who experience pain } \\
\text { despite maximization of non-opioid } \\
\text { therapy, it is recommended to continue } \\
\text { with the current therapy rather than a trial } \\
\text { of opioids. }\end{array}$ & Weak \\
\hline $\begin{array}{l}\text { 6. Prescribed opioid dosage is } \\
\text { recommended to be less than } 90 \mathrm{mg} \\
\text { morphine equivalents daily (MED). }\end{array}$ & Strong \\
\hline $\begin{array}{l}\text { 7. For patients beginning opioid therapy, } \\
\text { evidence suggests limiting the first } \\
\text { prescribed dose to less than } 50 \mathrm{mg} \text { MED } \\
\text { to reduce risk of nonfatal overdose or } \\
\text { deaths. }\end{array}$ & Weak \\
\hline $\begin{array}{l}\text { 8. There is evidence to suggest that } \\
\text { cyclical prescription to other opioids may } \\
\text { mediate dose reduction in patients who } \\
\text { have persistent pain despite using opioids. }\end{array}$ & Weak \\
\hline $\begin{array}{l}\text { 9. For those consuming more than } 90 \text { mg } \\
\text { MED, there is evidence to support tapering } \\
\text { opioids to the lowest effective dose with } \\
\text { the aim of opioid cessation, if possible, } \\
\text { rather than maintaining a consistent } \\
\text { regimen. }\end{array}$ & Weak \\
\hline $\begin{array}{l}\text { 10. There is strong evidence to suggest the } \\
\text { use of a formal multidisciplinary program } \\
\text { for opioid-consuming patients } \\
\text { encountering serious challenges in } \\
\text { tapering. }\end{array}$ & Strong \\
\hline
\end{tabular}

Accompanying the recommendations in this clinical guideline, the good practice statements are supported by indirect evidence, represent common-sense practice, and are associated with assumed large net benefit. These include informed consent, monitoring and adjusting the opioid therapy, and understanding the potential contraindications to opioid prescription. Lastly, the expert guidance provides direction in an area for which there is little or no published evidence. The guidance statements also include strategies for mitigating risks including urine drug screening, treatment agreements, tamper-resistant formulations, fentanyl patch exchange and naloxone kits.

\section{MULTI-PRONGED STRATEGIES NEEDED IN COMBATING THE OPIOID CRISIS}

While these clinical guidelines are necessary to promote best-practice prescribing patterns, they are not sufficient. Other strategies must be implemented simultaneously in order to curb opioid abuse. Evidenced-based clinical guidelines are certainly necessary to optimize prescribing behaviours and mitigate opioid overuse, dependency, and addiction. Trends in opioid dispensing and associated adverse events must be closely monitored to evaluate the impact of public health and policy interventions. Medical colleges across Canada have committed to establishing a national narcotics monitoring network to identify prescribing practices among physicians, high-risk prescribing behaviours and at-risk patients. This information can then be reported back to regulatory bodies. ${ }^{20}$ The network will also allow physicians to compare their prescribing practices with peers, promote harm reduction measures, and optimize the use of opioids. However, there may be a downside to this increased monitoring. Physicians may be punished for prescribing higher volumes of opioids which could lead to undertreatment of pain. Additionally, the information gathered can help modify postoperative pain management practices, especially in surgical specialties, with long-term opioid therapy. ${ }^{20}$

Over-prescription of opioid analgesics by physicians is only one of many contributors to the growing opioid crisis. To curb opioid use and abuse, it is imperative to not only treat the physical symptoms of pain but also address upstream factors contributing to pain. Interdisciplinary pain treatment centres (IPTC) recognize pain in a collaborative approach with pain specialists, physical therapists, chiropractors, acupuncturists, massage therapists, mental health providers and addiction specialists. This holistic approach, through a biopsychosocial lens, incorporates nonpharmacological modalities, such as cognitive behaviour therapy (CBT) and mindfulness meditation.,14,20 A meta-analysis of 65 studies reported an additional $20 \%$ reduction in pain with IPTC in comparison to pharmacotherapy. ${ }^{22}$ Further supporting these findings, a systematic review with 3089 patient participants found a pain reduction of $37 \%$ in the CBT group vs $4 \%$ in the control. ${ }^{23}$ In a wide range of studies, IPTC therapy proves to positively impact the perception of pain and pain behavior, in addition to enhancing pain-coping skills, physical function, and psychosocial well-being. ${ }^{21,24,25}$ Moreover, there is evidence for increased return to 
work in an IPTC vs a unimodal treatment model (68\% vs $32 \%)^{23}$ Interestingly, a study by Okifuji et al (1999) found a significant decline in the number of patients using opioids post-IPTC therapy in comparison to consumption at the time of program enrollment from $65 \%$ to $20 \%{ }^{26}$

Multidisciplinary approach to pain management has been recommended as a treatment modality by the International Association for the Study of Pain in addition to several Canadian provincial Colleges of Physicians and Surgeons. ${ }^{27,28}$ Currently, multidisciplinary chronic pain centres are limited to urban areas, leaving sub-urban and rural areas with poor accessibility. In conjunction with holistic pain management practices, the issue of illicit use of opioids also needs to be addressed. Access to harm reduction services, including supervised consumption sites and overdose prevention programs, will be instrumental to improve unsafe injection practices, reduce overdose morbidity and mortality, and facilitate detoxification and addiction treatment. ${ }^{29}$

\section{SUMMARY}

As opioid-related morbidity and mortality increases in Canada, addressing this public health crisis will be paramount for individual and societal health. While clinical guidelines have been updated to advise best-practice prescribing behaviours, multi-pronged systemic approaches will be key to tackle the complex roots of the opioid epidemic. Interdisciplinary treatment modalities for pain management have provided considerable evidence not only for pain reduction, but also for improved physical functioning, psychosocial wellbeing, and quality of life. Harm reduction programs should also be established across the nation to mitigate adverse health outcomes of substance abuse and addiction. Physicians are at the front-line of the opioid crisis and as such, have an onus to their patients to advocate for such systemic changes to address pain management in a holistic, patient-centered approach and provide meaningful solutions to end Canada's epidemic of opioid abuse.

\section{REFERENCES}

1. Busse J, Craigie S, Juurlink DN, et al. Guideline for opioid therapy and chronic noncancer pain. CMAJ. 2017; 189(18);e659-66.

2. Reitsma ML, Tranmer JE, Buchanan DM, et al. The prevalence of chronic pain and pain-related interference in the Canadian population from 1994 to 2008. Chronic Diseases and Injuries in Canada. 2011;31(4):157-64.

3. Hogan ME, Taddio A, Katz J et al. Health utilities in people with chronic pain using a population-level survey and linked health care administrative data. Pain. 2017;158:408-16

4. Loeser JD. Economic implications of pain management. Acta Anaesthesiol Scand. 1999;43:957-9.

5. Lynch ME. The need for a Canadian pain strategy. Pain Research \& Management 2011;16:77-80.

6. International Narcotic Control Board. Narcotic Drugs Technical report: Estimated World Requirements for 2017 - Statistics for 2015. 2017.

7. Gomes T, Mamdani MM, Dhalla IA, et al. The burden of premature opioidrelated mortality. Addiction. 2014;109(9):1482-8.

8. Todd KH, Ducharme J, Choiniere M, et al. Pain in the emergency department: Results of the Pain and Emergency Medicine Initiative (PEMI) multicenter study. Journal of Pain. 2007;8(6):460-6.
9. Rosenblum A, Marsch LA, Joseph H, et al. Opioids and the treatment of chronic pain: Controversies, current status, and future directions. Experimental and Clinical Psychopharmacology. 2008;16(5):405-16.

10. Van Zee A. The promotion and marketing of oxycontin: commercial triumph, public health tragedy. American Journal of Public Health. 2009;99(2):221-7.

11. Howlett K, Grant K. CAMH urges Ottawa to Take High-Dose Opioids off the Market [Internet]. The Globe and Mail. 2016 November 7 [cited 2017 Nov 20]. Available from: http://www.theglobeandmail.com/news/national/camh-urgesottawa-to-take-high-doseopioids-off-the-market/article32695249/.

12. Ho J, DeBeck K, Milloy MJ, et al. Increasing availability ofillicit and prescription opioids among people who inject drugs in a Canadian setting, 2010-2014. The American Journal of Drug and Alcohol Abuse. 2017.

13. Cheng T, Small W, Nosova E, et al. Nonmedical prescription opioid use and illegal drug use: initiation trajectory and related risks among people who use illegal drugs in Vancouver, Canada. BMC Research Notes. 2018;11:35

14. Curb prescriptions to combat opioid crisis. CMAJ. 2017;189:E46-7.

15. Canadian Institute for Health Information, Canadian Centre on Substance Abuse. Hospitalizations and Emergency Department Visits Due to Opioid Poisoning in Canada. 2016 [cited 2017 Nov 20] Available from: https://secure.cihi. ca/free_products/Opioid\%20Poisoning\%20Report\%20\%20EN.pdf.

16. Woo A, Howlett K. Fentanyl now leading cause of opioid deaths in Ontario [Internet]. The Globe and Mail. 2016 Feb 21 [cited 2017 Nov 20]. Available from: http://www.theglobeandmail.com/news/national/fentanyl-now-leading-causeof-opioid-deaths-in-ontario/article28832627/

17. Kaplovitch E, Gomes T, Camacho X, et al. Sex differences in dose escalation and overdose death during chronic opioid therapy: a population-based cohort study. PLoS One. 2015;10(8):e0134550.

18. Fischer B, Rehm J, Tyndall M. Effective Canadian policy to reduce harms from prescription opioids: learning from past failures. CMAJ. 2016;188:1240-4

19. A province-by-province look at opioid-overdose stats, including fentanyl [Internet]. Global News. 2016 Nov 17 [cited 2017 Nov 20]. Available from: https:// globalnews.ca/news/3072316/a-province-by-province-look-at-opioid-overdosestats-including-fentanyl/

20. Physicians combat opioid crisis. CMAJ. 2017;189:E44-5.

21. Stanos S. Focused Review of Interdisciplinary Pain Rehabilitation Programs for Chronic Pain Management. Curr Pain Headache Rep. 2012;16:147-152.

22. Flor H, Fydrich T, Turk DC. Efficacy of multidisciplinary pain treatment centers: a meta-analytic review. Pain. 1992; 49:221-230.

23. McCracken L and Turk D. Behavioral and Cognitive-behavioral treatment for chronic pain. Spine. 2002; 27:2564-73.

24. Jeffery MM, Butler M, Stark A, et al. Multidisciplinary Pain Programs for Chronic Noncancer Pain. Technical brief. Agency for Healthcare Research and Quality, Minneapolis MN. 2011. Available at: https://www.effectivehealthcare. ahrq.gov/ehc/products/212/760/TechBrief8_PainProgramsCancer_20110930.pdf

25. Becker N, Sjøgren P, Besh P, et al. Treatment outcome of chronic non-malignant pain patients managed in a danish multidisciplinary pain centre compared to general practice: a randomised controlled trial. Pain. 2000; 84:203-211.

26. Okifuji AA, Turk DC, Kalauokalani D, et al. Clinical outcomes and economic evaluation of the Multidisciplinary Pain Centers. In: Block A, Kremer EE, Fernandez E, editors. Handbook of Pain Syndromes. Mahwah, NJ: Lawrence Erlbaum Publishers; 1999. pp. 77-97.

27. International Association for the Study of Pain. Pain Treatment Services. 2009. Available at: http://www.iasp-pain.org/Education/Content. aspx?ItemNumber=1381.

28. Peng P, Choiniere M, Dion D, et al. Challenges in Accessing Multidisciplinary Pain Treatment Facilities in Canada. Can. J. Anaes. 2007; 54: 963-8.

29. Kerr T, Mitra S, Kennedy MC, et al. Supervised injection facilities in Canada: past, present, and future. Harm Reduction Journal. 2017; 14:28. 